\title{
Small practice effects on neurocognitive testing - markers of early cognitive impairment among adolescents with SLE?
}

\author{
Eyal Muscal ${ }^{1 *}$, Debra L Canter ${ }^{1}$, Douglas R Bloom', Barry L Myones' ${ }^{1}$, Stephen L Holliday ${ }^{3}$, Robin L Brey² \\ From 2011 Pediatric Rheumatology Symposium sponsored by the American College of Rheumatology \\ Miami, FL, USA. 2-5 June 2011
}

\section{Purpose}

Neurocognitive impairment is a prevalent feature of SLE. There is a paucity of data on the longitudinal assessment of cognitive performance of pediatric patients. There is no consensus on the timing of repeated neuropsychological evaluation in this population.

\section{Objective}

To describe longitudinal changes for both a traditional neuropsychological battery (TNPB) and the computerized Pediatric-Automated Neuropsychological Assessment Metrics (Ped-ANAM) among adolescents with SLE. We hypothesized there would be improvement in scores typical of practice effects among patients with minimal disease activity.

\section{Methods}

TNPB, Ped-ANAM, quality of life (PedsQL), and depression scales (CDI-S) were administered by psychology associates blinded to clinical status at two research visits. Differences in mean TNPB standardized scores, PedANAM throughput scores (raw Throughput=correct responses/minute), and clinical variables between visits were compared using paired Student t-tests. Multi-variable linear regression analysis was used to assess the influence of initial test performance, aPL/LAC status, disease duration, and cumulative prednisone dosing on composite TNPB or Ped-ANAM scores at a second visit.

\section{Results}

Twenty adolescents without active NPSLE were evaluated at two time points (mean of $6.2 \pm 1.8$ months apart). Mean age at first visit was $15.8 \pm 1.4$ years (range 13-18; 95\% female, 50\% Hispanic, $25 \%$ AfricanAmerican). Disease duration at entry was $22.5 \pm 12.6$ months. Only 2 patients (10\%) had a NPSLE history prior to study entry, and $3(15 \%)$ a history of biopsyproven nephritis. Cerebral volume loss was observed on $3 \mathrm{~T}$ anatomic MRIs of 12 subjects (60\%). SLEDAI and SLICC scores were low and not statistically different between visits ( $<4$ and $<1$ respectively). A history of LAC or aPL positivity was present in $8(40 \%)$ and 16 $(80 \%)$, respectively, at study entry. Full scale IQ scores were within average range $(102.0 \pm 9.0$ points $)$, and unchanged between visits. Mean depression and quality of life indices scores did not reflect distress at either visit. The lowest mean TNPB scores at both visits were on tests of verbal fluency and visual-motor integration. There were small improvements in the majority of individual TNPB and Ped-ANAM scores ( $Z$ score mean increase $0.19 \pm 0.14$ for TNPB and $0.48 \pm 0.41$ for PedANAM tests). TNPB test score improvements were often smaller than those described in normative population validation studies. Significant improvements were observed on the Ped-ANAM subscales of Code Substitution-Delayed $(\mathrm{Z}$ change $=0.63, \mathrm{p}=0.02)$ Logical Relation ( $\mathrm{Z}$ score change $=0.71, \mathrm{p}<0.01)$ and Spatial Processing $(\mathrm{Z}$ change $=1.3, p<0.01)$. Significant decrements were observed on the Trail-Making Test $B(Z=-0.8, p<0.05)]$ and two Ped-ANAM tests [Math Processing $Z=-0.77$, $\mathrm{p}<0.01$ and Procedural Reaction $Z=-1.0, \mathrm{p}<0.01]$. Visit 1 composite NP scores were the only significant predictors of visit 2 composite scores in multivariable regression analyses (TNPB $\beta=0.44, p=0.03$ and Ped-ANAM $\beta=0.62$, $\mathrm{p}<0.01)$.

Baylor College of Medicine, Houston, TX, USA

Full list of author information is available at the end of the article

(c) 2012 Muscal et al; licensee BioMed Central Ltd. This is an Open Access article distributed under the terms of the Creative Commons Attribution License (http://creativecommons.org/licenses/by/2.0), which permits unrestricted use, distribution, and reproduction in any medium, provided the original work is properly cited. 


\section{Conclusion}

Smaller than expected practice effects may reflect impaired learning ability early in the disease course of adolescents with SLE. Replication with larger controlled samples, and longer follow-up is planned.

\section{Disclosure}

Eyal Muscal: None; Debra L. Canter: None; Douglas R. Bloom: None; Barry L. Myones: None; Stephen L. Holliday: None; Robin L. Brey: None.

\section{Author details}

${ }^{1}$ Baylor College of Medicine, Houston, TX, USA. ${ }^{2}$ University of Texas Health Science Center, San Antonio, San Antonio, TX, USA. ${ }^{3}$ US Dept. of Veterans Affairs, San Antonio, TX, USA.

Published: 13 July 2012

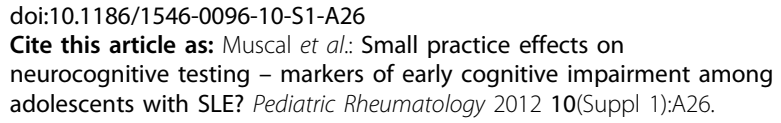

Submit your next manuscript to BioMed Central and take full advantage of:

- Convenient online submission

- Thorough peer review

- No space constraints or color figure charges

- Immediate publication on acceptance

- Inclusion in PubMed, CAS, Scopus and Google Scholar

- Research which is freely available for redistribution

Submit your manuscript at www.biomedcentral.com/submit 